University of Nebraska - Lincoln

DigitalCommons@University of Nebraska - Lincoln

February 2003

\title{
Reward Value of Cigarette Smoking for Comparably Heavy Smoking Schizophrenic, Depressed, and Nonpatient Smokers
}

\author{
Bonnie Spring \\ Regina Pingitore \\ Dennis E. McChargue \\ University of Nebraska-Lincoln, dmcchargue2@unl.edu
}

Follow this and additional works at: https://digitalcommons.unl.edu/psychfacpub

Part of the Psychiatry and Psychology Commons

Spring, Bonnie; Pingitore, Regina; and McChargue, Dennis E., "Reward Value of Cigarette Smoking for Comparably Heavy Smoking Schizophrenic, Depressed, and Nonpatient Smokers" (2003). Faculty Publications, Department of Psychology. 260.

https://digitalcommons.unl.edu/psychfacpub/260

This Article is brought to you for free and open access by the Psychology, Department of at DigitalCommons@University of Nebraska - Lincoln. It has been accepted for inclusion in Faculty Publications, Department of Psychology by an authorized administrator of DigitalCommons@University of Nebraska - Lincoln. 


\section{Reward Value of Cigarette Smoking for Comparably Heavy Smoking Schizophrenic, Depressed, and Nonpatient Smokers}

\author{
Bonnie Spring, Ph.D. \\ Regina Pingitore, Ph.D. \\ Dennis E. McChargue, Ph.D.
}

\begin{abstract}
Objective: The study goal was to determine whether schizophrenic and depressed smokers perceive the reinforcement value of cigarette smoking differently from nonpsychiatric smokers who smoke as heavily.
\end{abstract}

Method: The authors assessed the preferences for smoking cigarettes versus engaging in other pleasant activities, the perceived advantages and disadvantages of smoking, and the amount of reinforcement that would be needed to attain smoking abstinence among 26 schizophrenic, 26 depressed, and 26 nonpsychiatric heavy smokers.

Results: Both schizophrenic and depressed participants chose smoking as their preferred activity more often than nonpsychiatric smokers, and they did not differ from each other. The patients also exceeded the comparison group in the benefits they ascribed to smoking and felt they would require more incentives to quit, but they attributed comparable drawbacks to smoking.

Conclusions: Schizophrenic and depressed smokers recognize many drawbacks associated with smoking, but compared to nonpatients who smoke as heavily, they also perceive more benefits and find cigarettes more appealing than alternative rewards. The heightened reward value of smoking warrants attention in tailoring tobacco control interventions for schizophrenic and depressed smokers.

(Am J Psychiatry 2003; 160:316-322)

C igarette smoking remains the greatest preventable cause of death and disease in the United States $(1,2)$. After declining steadily for several decades, the prevalence of smoking stabilized in 1990 and since has decreased only minimally (3). The plateau in the smoking rate derives partly from several subpopulations of recalcitrant smokers who have been unable to quit $(4,5)$.

Schizophrenic and depressed smokers are two subgroups that have been especially difficult to reach. A decade-long antismoking campaign that made most hospitals smoke-free (6-8) has done little to decrease rates of smoking by psychiatric patients. Nor have either generic or selectively targeted treatments achieved notable success in promoting smoking cessation among either schizophrenic (9-12) or depressed (13, 14) individuals. Only about $1 \%$ of the population is affected by schizophrenia, but the prevalence of nicotine dependence among schizophrenic people is very high $(58 \%-92 \%)(15-18)$. Major depression affects about $15 \%$ of the population and has a smoking prevalence rate of $31 \%-61 \%(15,19,20)$, higher than that for the general population $(20 \%-30 \%)$ (3) but lower than that for schizophrenia. Thus, comorbidity of nicotine dependence with these two forms of psychopathology affects a substantial segment of the population, adding to health care expenditures (21-23). Higher rates of smoking in schizophrenia and depression cannot be ex- plained by differences in socioeconomic status, occupation, education, marital status, caffeine intake, or institutionalization, because they persist even after the effects of these confounding variables are taken into account (15).

The influences that make schizophrenic patients especially likely to smoke could be the same ones that lead depressed individuals to smoke, or they could differ. Consequently, we tested two alternative hypotheses: 1) diagnostic specificity: that schizophrenic patients find smoking more rewarding than depressed patients, and 2) psychopathologic commonality: that schizophrenic and depressed smokers find smoking similarly more rewarding than do comparison smokers without psychiatric disorders other than nicotine dependence.

The substantially higher prevalence of smoking in schizophrenia than depression suggests diagnostic specificity, which might reflect schizophrenia's unique pathophysiology or treatment. For example, schizophrenic patients may smoke to reduce the side effects of neuroleptic medications (24), although support for that proposition has been mixed (25-27). Also, schizophrenic patients may smoke to alleviate negative symptoms (11). Nicotine may be particularly reinforcing in schizophrenia because it stimulates the subcortical reward system and the prefrontal cortex, which both appear to be hypofunctional in schizophrenia (28-30). Through its action at nicotinic 
cholinergic receptors, nicotine increases firing of dopamine neurons in mesocorticolimbic pathways, enhancing dopamine release in both the nucleus accumbens and prefrontal cortex (28). Dopamine deficiency and low metabolic activity in these regions have been linked to the negative symptoms (29) and sensory gating deficits (31) that characterize schizophrenia.

Alternatively, smoking might function to ameliorate behavioral and biological vulnerabilities that are shared by schizophrenic and depressed individuals. For example, self-administering nicotine through smoking might transiently help to ameliorate anhedonia: a diminished capacity for pleasure that is evident in both schizophrenia and depression $(32,33)$. Nicotine's ability to directly trigger dopamine release in mesolimbic reward centers may render smoking one of few remaining reinforcers that schizophrenic and depressed patients experience as pleasurable (34). There are functional interactions between the cholinergic system and other neurotransmitter systems (e.g., glutamate, $\gamma$-aminobutyric acid [GABA], serotonin) that are abnormal in the two disorders. Self-administering nicotine may, therefore, serve to medicate affective, cognitive, and behavioral problems that arise from dysfunction in several neurotransmitter systems $(28,35,36)$.

In this study we compared several aspects of the reinforcing value of smoking for schizophrenic, depressed, and nonpsychiatric comparison subjects. One facet was the perceived advantages ("pros") and disadvantages ("cons") associated with smoking. We predicted that a decisional "balance sheet" of either the patients generally or the schizophrenic patients particularly would show that their perception tipped more strongly than that of comparison subjects toward believing that the pros of smoking outweigh the cons. We further expected that the biased decisional balance would result from the perception that smoking has both more pros and fewer cons than perceived by the comparison subjects. The rationale for predicting greater pros was that smoking should serve as a potent negative reinforcer particularly for schizophrenic patients, and perhaps more generally for psychiatric patients, because it dispels troublesome psychiatric symptoms (e.g., negative symptoms and medication side effects for schizophrenic patients, attentional problems and dysphoric mood for both schizophrenic and depressed patients). The rationale for predicting fewer perceived cons of smoking was that the cognitive deficits and social isolation that occur especially in schizophrenia but also in depression (37-39) might insulate patients from learning to fully appreciate the negative consequences of smoking.

In addition to the perceived pros and cons of smoking, we also evaluated two other aspects of smoking's reward value. One was participants' reported preferences for engaging in smoking rather than alternative pleasant activities. We expected that either the schizophrenic patients specifically or both psychiatric groups would show greater than normal preferences for smoking over other activities.
The rationale was that smoking may remain one of few dependable sources of pleasure by virtue of its ability to directly trigger dopamine release. Finally, we also appraised reward value by quantifying how much of each of a variety of rewards smokers felt they would require in order to quit smoking permanently. We predicted that schizophrenic patients particularly or patients generally would feel they needed greater than normal rewards to quit.

To validly test the study hypotheses, the research design needed to control for smoking rate. Otherwise, apparent differences between patients and normal subjects could arise spuriously from the fact that patients, especially schizophrenic ones, tend to smoke heavily (15). So that differences between psychiatric and nonpsychiatric smokers would not be attributable to different smoking rates, we compared psychiatric outpatients to a normal comparison group of firefighters, a group characterized by heavy smoking (40).

\section{Method}

The study had 78 participants: 26 with schizophrenia (disorganized subtype, $\mathrm{N}=9$; paranoid, $\mathrm{N}=9$; catatonic, $\mathrm{N}=4$; undifferentiated, $N=4), 26$ with major depression (recurrent in all cases), and 26 nonpsychiatric comparison smokers. The schizophrenic and depressed subjects were outpatients receiving treatment at an urban psychiatric rehabilitation center. All of the schizophrenic patients were taking typical neuroleptics; the depressed patients were taking either selective serotonin reuptake inhibitors or tricyclic antidepressants. The nonpsychiatric comparison smokers were employees at a local fire station. The eligibility criteria required that participants be older than 18 years of age, smoke more than 15 cigarettes per day, and lack evidence of gross cognitive impairment (evidenced by a Mini Mental State Examination [41] score higher than 24).

A pilot study was conducted to determine whether the schizophrenic and depressed patients could be diagnosed reliably on the basis of chart review and whether the nonpatients' screening interview reports of psychiatric symptoms corresponded to the results of semistructured interviews. An advanced clinical psychology graduate student administered the patient version of the Structured Clinical Interview for DSM-III-R (SCID) (42) to seven schizophrenic patients and five depressed patients from the rehabilitation center and the nonpatient version to five firefighters. Findings of $100 \%$ concordance between the SCID and chart review diagnoses for the patients and between the SCID and screening interview diagnoses for the nonpatients supported the use of screening interview diagnoses, supplemented for patients by chart review.

Nonpsychiatric comparison smokers were excluded if they presented evidence of any current or past axis I disorder other than nicotine dependence. Psychiatric participants were excluded if they exhibited comorbid axis I disorders other than schizophrenia, depression, and nicotine dependence. Those with schizoaffective disorder were excluded. The interviewer also assessed demographic and smoking characteristics and administered the Fagerstrom Tolerance Questionnaire (43) to measure physical dependence on nicotine. After complete description of the study to the subjects, written informed consent was obtained. Assessments were usually performed on a single day, during which participants could take smoking breaks.

Perceived pros and cons of smoking were assessed by a modified 28-item version of the Decisional Balance Scale (44). Partici- 
TABLE 1. Demographic and Smoking Characteristics of Schizophrenic, Depressed, and Nonpsychiatric Heavy Smokers

\begin{tabular}{|c|c|c|c|c|c|c|}
\hline \multirow[b]{2}{*}{ Characteristic } & \multicolumn{2}{|c|}{$\begin{array}{c}\text { Patients With } \\
\text { Schizophrenia }(\mathrm{N}=26)\end{array}$} & \multicolumn{2}{|c|}{$\begin{array}{c}\text { Patients With } \\
\text { Major Depression }(\mathrm{N}=26) \\
\end{array}$} & \multicolumn{2}{|c|}{$\begin{array}{c}\text { Nonpsychiatric } \\
\text { Comparison Subjects }(\mathrm{N}=26)\end{array}$} \\
\hline & Mean & SD & Mean & SD & Mean & SD \\
\hline$\overline{\text { Age }(\text { years) }}{ }^{\mathrm{a}}$ & 40.00 & 10.85 & 35.31 & 11.13 & 26.20 & 11.69 \\
\hline Education (years) & 11.81 & 2.15 & 13.21 & 2.24 & 12.96 & 1.01 \\
\hline Packs smoked per day & 1.85 & 0.85 & 1.83 & 0.84 & 1.81 & 0.72 \\
\hline Age when smoking began (years) & 15.88 & 5.46 & 14.50 & 4.56 & 14.73 & 3.64 \\
\hline Score on Fagerstrom Tolerance Questionnaire & 9.04 & 1.68 & 9.00 & 1.57 & 7.54 & 1.82 \\
\hline
\end{tabular}

a Significant difference among groups $(F=10.2, d f=2,76, p<0.001)$.

${ }^{\mathrm{b}}$ Significant difference among groups $(\mathrm{F}=6.6, \mathrm{df}=2,76, \mathrm{p}<0.01)$.

pants indicated their agreement with 14 possible advantages and 14 possible disadvantages of smoking by rating each item 1 (disagree), 2 (agree), or 3 (strongly agree). The scale was altered to make it more suitable for psychiatric patients by simplifying the wording, making it appropriate for administration by an interviewer, and adding items to assess positive and negative effects on psychiatric symptoms (e.g., "When I smoke, I enjoy everything more in life"; "Sometimes smoking makes me hear noises, voices, or sounds that other people don't hear"). Each subscale score ranged from 14 to 42 , and internal consistency was high for both the pro (Cronbach's alpha $=0.81$ ) and con (alpha $=0.82$ ) subscales. A decisional balance index was also computed by converting the scores on both subscales to $\mathrm{z}$ scores and subtracting the score for cons from the score for pros (44).

Preferences for engaging in smoking versus other rewarding activities were measured by a questionnaire developed for this study. The test required participants to make 15 forced choices between smoking and a variety of rewards likely to be accessible and enjoyed by psychiatric patients (e.g., eating their favorite candy, seeing a movie, receiving a gift). The choice of smoking was scored as 1 ; the choice of the other reward was scored as 0 . Scores on the preferences questionnaire ranged from 0 to 15 , and the test exhibited acceptable internal consistency (alpha=0.74).

The magnitude of reward felt necessary for quitting was measured by a rewards questionnaire created for this study. The questionnaire asked how much of each of 15 rewards (e.g., candy, coffee, money) participants would need to quit smoking permanently. The amount of each reward was scored from 1 to 7 , yielding a total score ranging from 15 to 105 . Higher numbers indicated a need for more rewards to quit smoking. Further information and copies of the test instruments are available from the first author on request.

\section{Results}

All three groups of participants were nicotine-dependent, heavy smokers who had smoked since their teenage years (Table 1). Univariate analysis of variance (ANOVA) detected no differences among the groups in the number of cigarettes smoked daily. The percentages of women in the three groups were as follows: schizophrenic, $26.9 \%(\mathrm{~N}=$ 7); depressed, $50.0 \%(\mathrm{~N}=13)$; comparison, $19.2 \%(\mathrm{~N}=5)$; lambda indicated that the proportion could not be predicted on the basis of diagnostic group. The patients were older and more physically dependent on nicotine (Table 1), so the analyses accounted for those differences. Age and Fagerstrom score were treated as covariates in the analyses of decisional balance, preferences for smoking, and rewards needed to quit, because the assumptions underlying analysis of covariance (ANCOVA) were met for these outcomes. ANCOVA could not be used to analyze pros and cons because the slopes of the regressions pre- dicting these outcomes from age and Fagerstrom score were not parallel across the groups. Therefore, for the analysis of pros and cons, age and Fagerstrom score were transformed to discrete variables and treated as ANOVA blocking factors, making it possible to examine any interactions with group (45). Age was dichotomized as $\leq 36$ years versus older, and Fagerstrom score was trichotomized as $\leq 7$ versus 8 versus $\geq 9$. Pros and cons were analyzed by two univariate ANOVAs rather than by multivariate analysis of variance, because they were uncorrelated $(\mathrm{r}=0.07, \mathrm{df}=78)$. For all analyses, two a priori orthogonal contrasts examined the alternative hypotheses that the schizophrenic patients differed from the depressed patients (diagnostic specificity) and that the two patient groups differed from the nonpatients (psychopathologic commonality).

Analysis of the decisional balance indexes, controlling for age and Fagerstrom score, indicated that the groups differed significantly $(\mathrm{F}=15.2, \mathrm{df}=2,73, \mathrm{p}<0.001)$. Consistent with psychopathologic commonality, the patients, compared to the normal subjects, attributed relatively greater advantages than disadvantages to smoking $(\mathrm{F}=27.9, \mathrm{df}=1$, $73, \mathrm{p}<0.001)$, and there were no significant differences between the schizophrenic and depressed patients. The positive decisional balances shown by the schizophrenic (mean=10.31, SD=4.74) and depressed (mean=11.81, SD= 3.29) smokers indicated that both groups appraised the advantages of smoking as greatly outweighing the disadvantages. In contrast, the index approached zero for the nonpsychiatric comparison subjects (mean $=0.42, \mathrm{SD}=3.52$ ), indicating that they judged the pros and cons of smoking nearly equivalent.

As expected, the groups differed significantly on how strongly they endorsed the pros of smoking (Figure 1), and there were no interactions with age or Fagerstrom score. Consistent with psychopathologic commonality, the patients exceeded the comparison subjects in the pros they ascribed to smoking $(\mathrm{F}=187.0, \mathrm{df}=1,75, \mathrm{p}<0.001)$. The scores of the schizophrenic patients (mean $=32.85, \mathrm{SD}=$ 3.71 ) and depressed patients (mean $=33.88, \mathrm{SD}=3.48$ ) did not differ significantly and were both higher than that of the comparison subjects (mean=22.77, $\mathrm{SD}=2.32$ ). Unexpectedly, the groups failed to differ in their perceptions of the negative consequences of smoking (comparison: mean=22.35, $\mathrm{SD}=2.87$; schizophrenic: mean $=22.54, \mathrm{SD}=$ 
FIGURE 1. Degree of Endorsement of 14 Pros and 14 Cons of Smoking by Schizophrenic, Depressed, and Nonpsychiatric Heavy Smokers ${ }^{\mathrm{a}}$

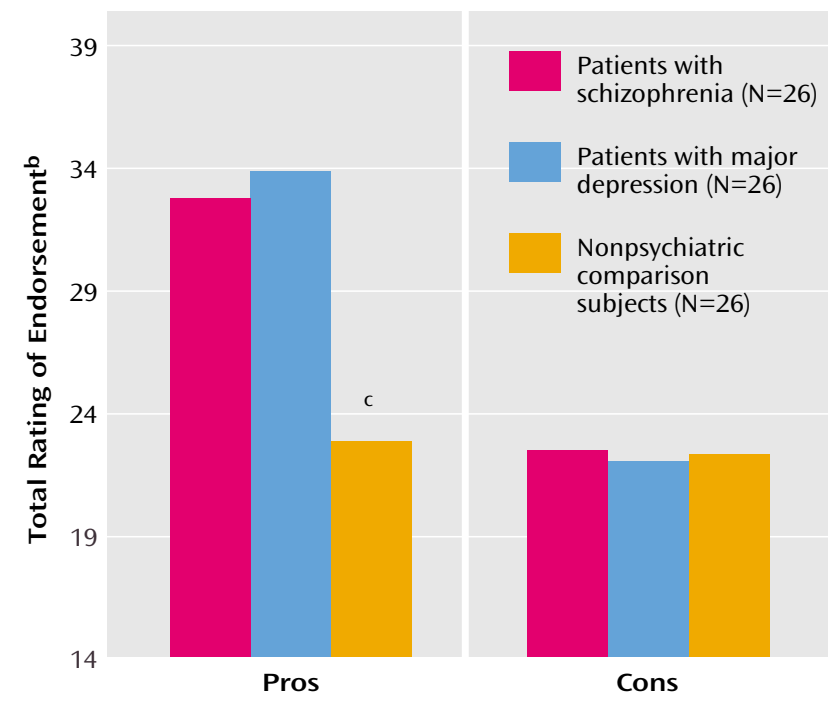

a Assessed with a modified version of the Decisional Balance Scale (44).

b $14=$ disagrees with all 14 pros/cons of smoking, $42=$ strongly agrees with all $14 \mathrm{pros} / \mathrm{cons}$ of smoking.

c Significant difference among groups $(F=75.6, d f=2,72, p=0.0001)$.

2.45; depressed: mean=22.08, $\mathrm{SD}=2.84$ ), and there was no interaction with age or Fagerstrom score. The results, shown in Figure 1, indicate that the schizophrenic and depressed patients recognized the disadvantages of smoking as fully as did the nonpsychiatric comparison smokers but considered them less impressive than the advantages.

Also supporting psychopathologic commonality, both patient groups exceeded the comparison subjects in their reported preferences for smoking rather than other pleasant activities, after age and Fagerstrom score were controlled for (Figure 2). Again, there was no difference between the schizophrenic and depressed patients. As shown in Figure 2, the average nonpsychiatric comparison subject chose smoking over other rewards in about $33 \%$ of the 15 choices (mean score $=5.27, \mathrm{SD}=1.04$ ), whereas the average schizophrenic and depressed patients preferred smoking in about $67 \%$ of the choices (schizophrenic: mean=10.42, $\mathrm{SD}=1.88$; depressed: mean=10.04, $\mathrm{SD}=1.87$ ).

Finally, controlling for age and Fagerstrom, we found that the groups differed in the magnitude of the rewards they would find necessary in order to quit smoking (Figure 3 ). Again, the schizophrenic (mean score $=102.65, \mathrm{SD}=$ 2.15) and depressed (mean $=102.62, \mathrm{SD}=2.52$ ) smokers failed to differ from each other. Both patient groups felt that quitting would require substantially more rewards than did the comparison smokers (mean=69.35, $\mathrm{SD}=7.93$ ).

\section{Discussion}

The results of this study indicate that both schizophrenic and depressed smokers associate greater advantages and
FIGURE 2. Degree of Preferences for Smoking Over 15 Alternative Rewards Reported by Schizophrenic, Depressed, and Nonpsychiatric Heavy Smokers

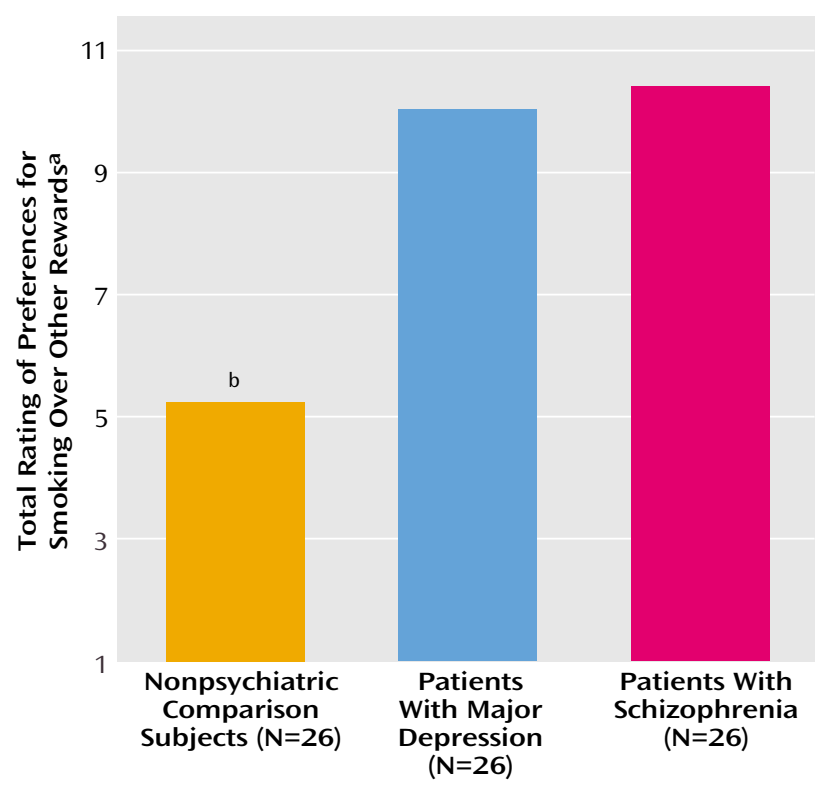

${ }^{\text {a }} 0=$ choose all other reward options in preference to smoking, $15=$ choose smoking in preference to all other reward options.

${ }^{b}$ Significant difference among groups $(F=54.3, d f=2,73, p=0.0001)$.

reward value with cigarette smoking than do individuals without psychiatric disorders who smoke as heavily. There were virtually no differences between the patient groups. The findings also show that the patients appreciated the drawbacks of smoking as fully as the nonpsychiatric comparison subjects but considered them outweighed by smoking's advantages. In contrast, the comparison subjects perceived the pros and cons of smoking as nearly equivalent. When asked to choose between smoking and other pleasant activities, the schizophrenic and depressed smokers chose smoking twice as often as the comparison subjects. Finally, the incentives that the patients said they would need to quit smoking approached the maximal possible reward magnitude, markedly exceeding what the comparison subjects said they would need.

The rarity of smoking cessation by schizophrenic and depressed smokers has remained largely unexplained. Candidate explanations have been that patients 1) have minimal contact with antismoking messages and little access to smoking cessation treatment, 2) are characterized by a preponderance of heavy smokers, or 3) experience nicotine effects on psychopathologic vulnerabilities that render the smoking habit exceptionally rewarding and difficult to break. The current prevalence of nonsmoking environments and media antismoking messages, coupled with the availability of over-the-counter cessation aids, make it increasingly implausible that psychiatric patients smoke because they are unaware of the risks or lack access to cessation resources. Indeed, the current findings contradict that premise, by showing that psychiatric patients 
FIGURE 3. Amounts of 15 Rewards Considered Necessary to Quit Smoking by Schizophrenic, Depressed, and Nonpsychiatric Heavy Smokers

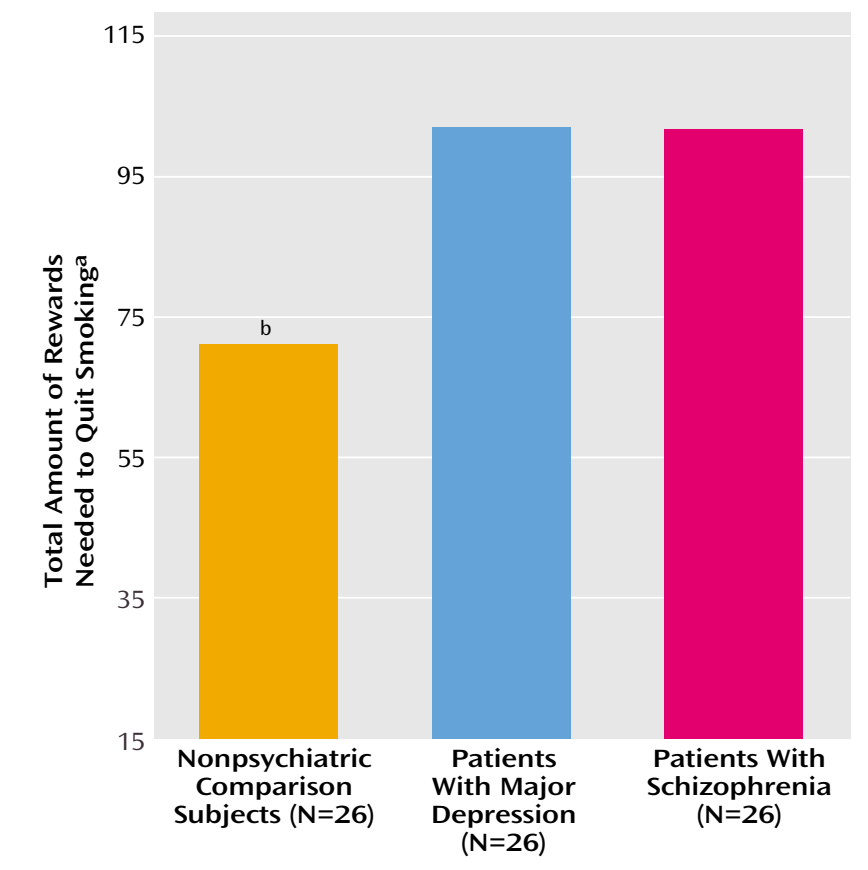

a $15=$ minimal other rewards needed to quit smoking (needs only 1 unit of each of 15 rewards), 150=maximal other rewards needed to quit smoking (needs 10 units of each of 15 rewards).

${ }^{b}$ Significant difference among groups $(F=12.5, d f=2,73, p=0.0001)$.

appreciate the disadvantages of smoking as adequately as smokers without major psychopathology.

These are, to our knowledge, the first findings to demonstrate that both schizophrenic and depressed patients attribute greater-than-normal reward value to cigarette smoking and that the difference is unlikely to be explained by variation in nicotine exposure. All three study groups, including the nonpsychiatric comparison subjects, smoked heavily (nearly two packs per day), and there was no difference among them in the amount smoked. It is interesting that, despite smoking equally heavily, the patients reported features (such as smoking soon after awakening) that suggest greater physical dependence on nicotine. That patients apparently exhibit greater nicotine dependence than nonpsychiatric comparison subjects, even given seemingly comparable nicotine exposure, is intriguing. Nevertheless, we think it unlikely that group differences in nicotine dependence can explain the greater reward value of cigarettes for smokers with other psychiatric disorders because our analyses controlled for them.

The lack of difference between schizophrenic and depressed smokers was surprising, especially given the higher prevalence of smoking usually observed among schizophrenic patients. Two explanations suggest themselves. One is that, by studying only heavy smokers, we selected depressed patients who were unrepresentative of that disorder but held many sociodemographic features in common with schizophrenic patients. An alternative explanation that seems more likely is that there may be genuine commonalities in what hooks schizophrenic and depressed smokers to their cigarettes. Plausibly, schizophrenic and depressed individuals share certain neurobiological features, either premorbidly or as a consequence of illness, medications, comorbid addictions, or even chronic nicotine exposure, that render nicotine a particularly appealing drug to self-administer. Earlier we posited that nicotine's ability to trigger dopamine release in mesolimbic reward centers might render smoking one of the few reinforcers able to overcome the anhedonia that characterizes schizophrenia and depression (28). Beneficial effects on other core affective and cognitive psychopathologic vulnerabilities may also occur (46), mediated by nicotine's effects on serotonin, glutamate, GABA, and acetylcholine (36).

Certain limitations of the current study need to be considered. First, the findings can be interpreted only as indicating that cigarette smoking (not necessarily nicotine) has disproportionate reward value for schizophrenic and depressed smokers. Laboratory experimental studies are needed to differentiate between the pharmacological effects of nicotine and the sensory effects of smoking on perceived reward. Second, the data were based on self-reports provided by psychiatric patients. Can such self-reports, particularly those of patients with schizophrenia, be considered valid? Some reassurance derives from the consistent pattern of group differences across all measures of smoking's reward value, from how closely the reports of the schizophrenic patients resembled those of the depressed outpatients, and from the fact that all of the groups seemed well informed of the negative consequences of smoking. Nevertheless, it would be advantageous for the results to be replicated by behavioral protocols not requiring participants to have any insight into their own motivations (see reference 47 ). Third, the generalizability of the findings remains unclear. The patients with psychiatric disorders had relatively high levels of functioning: the groups included only patients who were able to live outside the hospital, manage their own appointment schedules, and pass the mental state entry criteria imposed for this study. It cannot be assumed that the results, perhaps particularly those showing full awareness of the disadvantages of smoking, would generalize to more severely impaired patient populations.

The results may have implications for smoking cessation treatment. Research guided by the transtheoretical model has shown that people progress through a series of stages in their readiness to initiate change in health-related behavior (48). The patients' motivational balance sheet, in which the pros of smoking outweighed the cons, is typical of people in the precontemplative stage of readiness to quit smoking. Smokers in the precontemplative stage recognize intellectually that they need to quit, but they are not actually intending to make an attempt to quit 
in the foreseeable future. To progress to the stage of contemplation, which involves seriously thinking about making an attempt to quit, the smoker needs to experience a decline in the perceived advantages of smoking. The heavy-smoking nonpatient participants in this study differed from the patients in showing a typical motivational balance for contemplators: one in which the perceived advantages of smoking have lessened and are roughly equivalent to its perceived drawbacks. The contemplator's likelihood of moving into the stage of preparing to make a quit attempt will be enhanced by experiences that enhance feelings of self-efficacy about being able to quit.

Enrollment in smoking cessation treatment has been shown to be unproductive until a smoker reaches the stage of at least contemplating, if not actively preparing to make, a quit attempt (49). If the patients in the current study are representative of other schizophrenic and depressed smokers in being at a very early stage of readiness to quit, referral to smoking cessation treatment would be premature and ineffectual. More appropriate and needed forms of tobacco control intervention for smokers with psychiatric disorders may involve motivational interviewing and other brief interventions that overcome barriers to considering healthy behavior change (50).

Received Oct. 2, 2001; revision received July 11, 2002; accepted July 18, 2002. From the Department of Psychology, University of Illinois at Chicago; and the Department of Biological Psychiatry, Edward Hines Jr. VA Hospital, Hines, Ill. Address reprint requests to Dr. Spring, ABPP, Department of Psychology (M/C 285), University of Illinois at Chicago, 1007 West Harrison St., Chicago, IL 60607; bspring@uic.edu (e-mail).

Supported in part by a VA Merit Review award to Dr. Spring, by a VA Merit Review Entry Program award to Dr. McChargue, by grants HL52577 and HL-59348 to Dr. Spring from the National Heart, Lung, and Blood Institute, and by grant DA-00467 to Dr. McChargue from the National Institute on Drug Abuse.

\section{References}

1. Tobacco use-United States, 1900-1999. MMWR Morb Mortal Wkly Rep 1999; 48:986-993

2. Peto R, Lopez AD, Boreham J, Thun M, Heath C Jr: Mortality from tobacco in developed countries: indirect estimation from national vital statistics. Lancet 1992; 339:1268-1278

3. Breslau N, Johnson EO, Hiripi E, Kessler R: Nicotine dependence in the United States: prevalence, trends and smoking persistence. Arch Gen Psychiatry 2001; 58:810-816

4. Abrams DB, Clark MM, King TK: Increasing the impact of nicotine dependence treatment: conceptual and practical considerations in a stepped-care plus treatment-matching approach, in Changing Addictive Behavior: Bridging Clinical and Public Health Strategies. Edited by Tucker JA, Donovan, DM. New York, Guilford, 1999, pp 307-330

5. Hajek P: Individual differences in difficulty quitting smoking. Br J Addict 1991; 86:555-558

6. Patten CA, Martin JE, Owen N: Can psychiatric and chemical dependency treatment units be smoke-free? J Subst Abuse Treat 1996; 13:107-118

7. Resnick MP: Treating nicotine addiction in patients with psychiatric co-morbidity, in Nicotine Addiction: Principles and
Management. Edited by Orleans CT, Slade JD. New York, Oxford University Press, 1993, pp 327-336

8. Ryabik BM, Lippmann SB, Mount R: Implementation of a smoking ban on a locked psychiatric unit. Gen Hosp Psychiatry 1994; 16:200-204

9. Addington J, el Guebaly N, Campbell W, Hodgins DC, Addington D: Smoking cessation treatment for patients with schizophrenia. Am J Psychiatry 1998; 155:974-976

10. George TP, Ziedonis DM, Feingold A, Pepper WT, Satterburg CA, Winkel J, Rounsaville BJ, Kosten TR: Nicotine transdermal patch and atypical antipsychotic medications for smoking cessation in schizophrenia. Am J Psychiatry 2000; 157:1835-1842

11. Ziedonis DM, George TP: Schizophrenia and nicotine use: report of a pilot smoking cessation program and review of neurobiological and clinical issues. Schizophr Bull 1997; 23:247254

12. Weiner E, Ball MP, Summerfelt A, Gold J, Buchanan RW: Effects of sustained-release bupropion and supportive group therapy on cigarette consumption in patients with schizophrenia. Am J Psychiatry 2001; 158:635-637

13. Pomerleau CS, Brouwer L, Namenek L, Pomerleau OF: Emergence of depression during early abstinence in depressed and non-depressed women smokers. J Addict Dis 2001; 20:73-80

14. Thorsteinsson HS, Gillin JC, Patten CA, Golshan S, Sutton LD, Drummond S, Clark CP, Kelsoe J, Rapaport M: The effects of transdermal nicotine therapy for smoking cessation on depressive symptoms in patients with major depression. Neuropsychopharmacology 2001; 24:350-358

15. Hughes JR, Hatsukami DK, Mitchell JE, Dahlgren LA: Prevalence of smoking among psychiatric outpatients. Am J Psychiatry 1986; 143:993-997

16. de Leon J, Dadvand M, Canuso C, White AO, Stanilla JK, Simpson GM: Schizophrenia and smoking: an epidemiological survey in a state hospital. Am J Psychiatry 1995; 152:453-455

17. Dalack GW, Healy DJ, Meador-Woodruff JH: Nicotine dependence in schizophrenia: clinical phenomena and laboratory findings. Am J Psychiatry 1998; 155:1490-1501

18. Kelly C, McCreadie RG: Smoking habits, current symptoms, and premorbid characteristics of schizophrenic patients in Nithsdale, Scotland. Am J Psychiatry 1999; 156:1751-1757

19. Breslau N, Kilbey M, Andreski P: Nicotine dependence, major depression, and anxiety in young adults. Arch Gen Psychiatry 1991; 48:1069-1074

20. Glassman AH, Helzer JE, Covey LS, Cottler LB, Stetner F, Tipp JE, Johnson J: Smoking, smoking cessation, and major depression. JAMA 1990; 264:1546-1549

21. Leslie DL, Rosenheck R: Shifting to outpatient care? mental health care use and cost under private insurance. Am J Psychiatry 1999; 156:1250-1257

22. Simon GE, Katzelnick DJ: Depression, use of medical services and cost-offset effects. J Psychosom Res 1997; 42:333-344

23. Wasylenki DA: The cost of schizophrenia. Can J Psychiatry 1994; 39(9 suppl 2):S65-S69

24. Jarvik M: Beneficial effects of nicotine. Br J Addict 1991; 86: 571-575

25. Menza MA, Grossman N, Van Horn M, Cody R, Forman N: Smoking and movement disorders in psychiatric patients. Biol Psychiatry 1991; 30:109-115

26. Levin ED, Wilson W, Rose JE, McEvoy J: Nicotine-haloperidol interactions and cognitive performance in schizophrenics. Neuropsychopharmacology 1996; 15:429-436

27. Dalack GW, Meador-Woodruff JH: Smoking, smoking withdrawal and schizophrenia: case reports and a review of the literature. Schizophr Res 1996; 22:133-141

28. Watkins SS, Koob GF, Markou A: Neural mechanisms underlying nicotine addiction: acute positive reinforcement and withdrawal. Nicotine Tob Res 2000; 2:19-37 
29. Weinberger DR, Berman KF, Illowsky BP: Physiological dysfunction of dorsolateral prefrontal cortex in schizophrenia, III: a new cohort and evidence for a monoaminergic mechanism. Arch Gen Psychiatry 1988; 45:609-615

30. Chambers RA, Krystal JH, Self DW: A neurobiological basis for substance abuse comorbidity in schizophrenia. Biol Psychiatry 2001; 50:71-83

31. Swerdlow NR, Geyer MA: Using an animal model of deficient sensorimotor gating to study the pathophysiology and new treatments of schizophrenia. Schizophr Bull 1998; 4:285-301

32. Fawcett J, Clark DC, Scheftner WA, Hedeker D: Differences between anhedonic and normally hedonic depressive states. Am J Psychiatry 1983; 140:1027-1030

33. Meehl PE: Hedonic capacity: some conjectures. Bull Menninger Clin 1975; 39:295-307

34. Gopalaswamy AK, Morgan R: Smoking in chronic schizophrenia (letter). Br J Psychiatry 1986; 149:523

35. Glassman AH: Cigarette smoking: implications for psychiatric illness. Am J Psychiatry 1993; 150:546-553

36. Balfour DJK, Ridley DL: The effects of nicotine on neural pathways implicated in depression: a factor in nicotine addiction? Pharmacol Biochem Behav 2000; 66:79-85

37. Goldberg TE, Gold JM, Greenberg R, Griffin S, Schultz SC, Pickar D, Kleinman JE, Weinberger DR: Contrasts between patients with affective disorders and patients with schizophrenia on a neuropsychological test battery. Am J Psychiatry 1993; 150: 1355-1362

38. Addington J, Addington D: Neurocognitive and social functioning in schizophrenia. Schizophr Bull 1999; 25:173-182

39. Tancer ME, Brown TM, Evans DL, Ekstrom D, Haggerty JJ Jr, Pederson C, Golden RN: Impaired effortful cognition in depression. Psychiatry Res 1990; 31:161-168
40. Ellam LD, Fieldman GB, Fordham M, Goldsmith R, Barham P: The perception of physical fitness as a guide to its evaluation in firemen. Ergonomics 1994; 37:943-952

41. Folstein MF, Folstein SE, McHugh PR: "Mini-Mental State": a practical method for grading the cognitive state of patients for the clinician. J Psychiatr Res 1975; 12:189-198

42. Spitzer RL, Williams JBW, Gibbon M, First MB: The Structured Clinical Interview for DSM-III-R (SCID), I: history, rationale, and description. Arch Gen Psychiatry 1992; 49:624-629

43. Fagerstrom KO: Measuring degree of physical dependence to tobacco smoking with reference to individualization of treatment. Addict Behav 1978; 3:235-241

44. Velicer WF, DiClemente CC, Prochaska JO, Brandenburg N: Decisional balance measure for assessing and predicting smoking status. J Pers Soc Psychol 1985; 48:1279-1289

45. Tabachnick BG, Fidell LS: Using Multivariate Statistics, 4th ed. Needham Heights, Mass, Allyn \& Bacon, 2001, p 303-304

46. Zubin J, Spring B: Vulnerability: a new view of schizophrenia. J Abnorm Psychol 1977; 86:103-126

47. Tidey JW, O'Neill SC, Higgins ST: Effects of abstinence on cigarette smoking among outpatients with schizophrenia. Exp Clin Psychopharmacol 1999; 7:347-353

48. Velicer WF, Norman GJ, Fava JL, Prochaska JO: Testing 40 predictions from the transtheoretical model. Addict Behav 1999; 24:455-469

49. Prochaska JO, DiClemente CC, Norcross JC: In search of how people change: applications to addictive behaviors, in Addictive Behaviors: Readings on Etiology, Prevention, and Treatment. Edited by Marlatt GA, VandenBos GR. Washington, DC, American Psychological Association Press, 1997, pp 671-696

50. Yahne CE, Miller WR: Enhancing motivation for treatment and change, in Addictions: A Comprehensive Guidebook. Edited by McCrady BS, Epstein EE. New York, Oxford University Press, 1999, pp 235-249 